\title{
PEMEKATAN UNSUR HARA MIKRO YANG TERDAPAT DALAM AIR LINDI TEMPAT PEMROSESAN AKHIR (TPA) SAMPAH
}

\author{
Faitur Rahmi ${ }^{1}$, Berlian Sitorus ${ }^{2}$, Robby Irsan ${ }^{1}$ \\ ${ }^{1}$ Program Studi Teknik Lingkungan, Fakultas Teknik, Universitas Tanjungpura, Pontianak \\ ${ }^{2}$ Program Studi Kimia, Fakultas MIPA, Universitas Tanjungpura, Pontianak \\ Email : ami_tujuhbelas17@yahoo.com
}

\begin{abstract}
ABSTRAK
Air lindi yang berasal dari tempat pemrosesan akhir sampah apabila tidak dikelola dengan baik maka akan berpotensi merusak lingkungan sekitar. Sehingga menimbulkan beberapa dampak negatif bagi kesehatan maupun sosial masyarakat. Disisi lain sebagai polutan, air lindi memiliki kandungan senyawa berupa logam-logam yang merupakan kandungan unsur hara mikro pupuk organik antara lain $\mathrm{Cu}, \mathrm{Fe}, \mathrm{Zn}$, dan $\mathrm{Mn}$. Penelitian ini bertujuan untuk mengolah air lindi yang berasal dari Tempat Pemrosesan Akhir (TPA) Batu Layang Kota Pontianak sehingga menghasilkan efluen yang pekat dengan unsur hara mikro. Penelitian ini diawali dengan pengolahan aerasi yang bertujuan untuk mengendapkan unsur hara mikro. Kemudian efluen dari pengolahan aerasi kembali dipekatan dengan penambahan larutan $\mathrm{CaO}$ untuk mengubah kelarutan unsur hara mikro, dan dioptimalkan kembali dengan membandingkan efektifitas pemekatan antara penambahan senyawa pengkelat $\mathrm{KMnO}_{4}$ dengan senyawa pengkelat EDTA. Selanjutnya dilakukan proses sentrifugasi untuk memisahkan flok-flok yang terbentuk dari kandungan air. Hasil akhir dari konsentrasi unsur hara mikro yang didapat setelah dilakukan proses pemekatan dengan penambahan senyawa $\mathrm{KMnO}_{4}$, diperoleh efisiensi pemekatan logam-logam antara lain yaitu tembaga $(\mathrm{Cu})=99.98 \%$, besi $(\mathrm{Fe})=96,55 \%$, mangan $(\mathrm{Mn})=99,56 \%$, dan seng $(Z n)=99,75 \%$, sedangkan proses pemekatan dengan penambahan senyawa EDTA diperoleh efisiensi pemekatan logam-logam antara lain yaitu tembaga $(\mathrm{Cu})=99,83 \%$, besi $(\mathrm{Fe})=99,10 \%$, mangan $(\mathrm{Mn})=99,86 \%$ dan seng $(\mathrm{Zn})=99,94 \%$. Berdasarkan nilai konsentrasi akhir yang didapatkan dari proses pemekatan unsur-unsur hara mikro, air lindi TPA Batu Layang berpotensi untuk dijadikan pupuk organik. Sedangkan senyawa kimia $\mathrm{KMnO}_{4}$ merupakan senyawa pengkelat terbaik dalam proses pemekatan unsur-unsur hara mikro dibandingkan dengan senyawa kimia EDTA yang digunakan dalam penelitian ini.
\end{abstract}

Kata kunci: air lindi, EDTA, $\mathrm{KMnO}_{4}$, unsur hara mikro

\begin{abstract}
Leachate from the land fill if not managed well, will potentially damage the surrounding environment and create a negative impact on the health and social community. On the other hand, leachate contains metals that are used as micro-nutrients for organic fertilizers such as $\mathrm{Cu}, \mathrm{Fe}, \mathrm{Zn}$ and $\mathrm{Mn}$. This research aims to treat the leachate from Batu Layang Landfill as of the effluent contained of micro-nutrients. The processing begins with aeration treatment to precipitate the micro-nutrients. This research aims to treat leachate from Batu Layang Landfill to create effluent that is full of micro-nutrients for organic fertilizers. This research began with the aeration treatment to precipitate the micro-nutrients. The effluent from the aeration process is concentrated again by adding $\mathrm{CaO}$ to change the solubility of the micro-nutrient, then it is optimised again by comparing the effectiveness of concentration between the addition of the chelating compound, KMnO4 or EDTA. The next step is the centrifugation process to separate the flocks created from the watersolution. The final result of the micro nutrients consentration are obtained from concentrated process by additional of $\mathrm{KMnO}_{4}$, was obtained concentration efficiency such as copper (Cu) $=99.98 \%$, iron $(\mathrm{Fe})=96.55 \%$, manganese $(\mathrm{Mn})=99.56 \%$, and $\mathrm{zinc}(\mathrm{Zn})=99.75 \%$, whereas the concentration process by the addition of EDTA compounds, obtained concentration efficiency such as copper $(\mathrm{Cu})=99.83 \%$, iron $(\mathrm{Fe})=99.10 \%$, manganese $(\mathrm{Mn})=99.86 \%$ and zinc $(\mathrm{Zn})=99.94 \%$. Based on the final concentration values obtained of the concentration process from micro nutrient, Batu Layang landfill leachate has ptential to be used as organic fertilizer. Whereas $\mathrm{KMnO}_{4}$ compounds are best chelating compounds in the concentration process of micro nutriens compared with EDTA compounds used in this research.
\end{abstract}

Keywords: leachate, EDTA, KMnO4, micro-nutrients 


\section{Latar Belakang}

Kota Pontianak memiliki TPA Batu Layang yang merupakan TPA (Tempat Pemrosesan Akhir) sampah, untuk menampung sampah hasil aktifitas yang dilakukan oleh masyarakat di kota Pontianak. TPA sampah ini bersifat open dumping, yaitu sampah dibiarkan terbuka, sehingga selain menimbulkan bau juga menghasilkan lindi yang mengandung beberapa polutan yang akan menimbulkan dampak negatif bagi lingkungan sekitar. Apabila pencemaran lindi terus dibiarkan, dikhawatirkan timbul keresahan masyarakat sekitar TPA.

Disisi lain sebagai pencemar, air lindi memiliki kandungan yang merupakan unsur hara mikro essensial dalam pupuk organik, antara lain unsur-unsur logam $\mathrm{Cu}, \mathrm{Fe}, \mathrm{Zn}$, dan $\mathrm{Mn}$. Namun demikian, Arya dan Gilar (2008) mengemukakan bahwa kandungan senyawa yang dibutuhkan tanaman yang terdapat pada lindi dari TPA sampah umumnya belum memenuhi standar seperti yang ditentukan oleh Departemen Pertanian RI sehingga pupuk organik cair dari lindi TPA sampah belum dapat langsung dipasarkan. Oleh karena itu, perlu upaya yang dapat mengendapkan hara dalam lindi TPA sampah agar hara yang ada menjadi lebih pekat dan lebih berdaya guna dalam meningkatkan pertumbuhan dan produksi tanaman.

Penelitian ini dilakukan untuk menentukan senyawa pengkelat yang terbaik anatara senyawa $\mathrm{KMnO}_{4}$ dan EDTA dalam proses pemekatan unsur-unsur hara mikro yang terdapat dalam air lindi hingga memenuhi standar persyaratan pupuk organik. Untuk itu air lindi diberikan beberapa tahapan pengolahan, diantaranya proses pengolahan aerasi yang bertujuan untuk mengendapakan unsur-unsur hara mikro sehingga diperoleh bahan air lindi yang lebih pekat dengan unsur-unsur hara mikro. Kemudian dilakukan penambahan larutan $\mathrm{CaO}$ untuk merubah kelarutan logam-logam unsur hara mikro yang selanjutnya dioptimalkan kembali dengan penambahan senyawa pengkelat. Sebagai proses akhir dilakukan proses sentrifugasi untuk memisahkan flok-flok yang mengadung unsur hara mikro dengan air.

\section{Tinjauan Pustaka}

A. Pengertian Umum Air Lindi

Lindi terbentuk di setiap lokasi pembuangan sampah. Pembentukan lindi merupakan hasil dari infiltrasi dan perkolasi (perembesan air dalam tanah) dari air hujan, air tanah, air limpasan atau air banjir yang menuju dan melalui lokasi pembuangan sampah (Nemerow dan Dasgupta, 1991). Iklim merupakan faktor penting yang mempengaruhi kuantitas dan kualitas lindi. Hujan menjadi fase transport untuk pencucian dan migrasi kontaminan dari tumpukan sampah.

\section{B. Parameter Air Lindi ( Leachete )}

1. Parameter Fisika

a. Suhu

Suhu suatu badan perairan dipengaruhi oleh musim, posisi lintang, ketinggian dari permukaan laut, waktu dalam hari, sirkulasi udara, penutupan awan, dan aliran serta kedalaman badan air.

\section{b. TSS ( Total Suspended Solid)}

TSS terdiri atas lumpur dan pasir halus serta jasad-jasad renik, yang terutama disebabkan oleh kikisan tanah atau erosi tanah yang terbawa ke badan air.

\section{Parameter Kimia}

a. $\mathrm{pH}$

Pescod (1973) mengatakan bahwa nilai pH menunjukkan tinggi rendahnya konsentrasi ion hidrogen dalam air. Kemampuan air untuk mengikat atau melepaskan sejumlah ion hidrogen akan menunjukkan apakah perairan tersebut bersifat asam atau basa (Barus, 2002).

\section{b. DO (Dissolved Oxygen)}

Oksigen terlarut (dissolved oxygen) merupakan konsentrasi gas oksigen yang terlarut dalam air. Faktor yang mempengaruhi jumlah oksigen terlarut di dalam air adalah jumlah 
kehadiran bahan organik, suhu, aktivitas bakteri, kelarutan, fotosintesis dan kontak dengan udara.

c. BOD (Biochemical Oxygen Demand)

Biochemical Oxygen Demand adalah jumlah oksigen yang diperlukan oleh mikroorganisme untuk menguraikan bahan organik yang terdapat dalam air pada keadaan aerobil.

\section{d. COD (Chemical Oxygen Demand)}

COD menyatakan jumlah total oksigen yang dibutuhkan untuk mengoksidasi semua bahan organik yang terdapat di perairan, menjadi $\mathrm{CO}_{2}$ dan $\mathrm{H}_{2} \mathrm{O}$. Pada prosedur penentuan COD, oksigen yang yang dikonsumsi setara dengan jumlah dikromat yang diperlukan dalam mengoksidasi air sampel.

\section{Pupuk Organik}

Pupuk organik merupakan pupuk dengan bahan dasar yang diambil dari alam dengan jumlah dan jenis unsur hara yang terkandung secara alami. Unsur hara rerdiri atas dua macam berdasarkan kebutuhan tanaman akan unsur tersebut, yaitu unsur hara makro dan unsur hara mikro. Unsur Hara Makro terdiri dari unsur Nitrogen (N), Posfor (P) dan Kalium (K), sedangakan unsur hara mikro terdiri dari Besi (Fe), Mangan (Mn), Seng ( $\mathrm{Zn}$ ) dan Tembaga (Cu)

\section{Pengolahan Aerobik dengan Cara Aerasi}

Aerasi adalah salah satu pengolahan air dengan cara penambahan oksigen ke dalam air. Tujuan utama aerasi adalah agar oksigen $\left(\mathrm{O}_{2}\right)$ di udara dapat bereaksi dengan kation yang ada di dalam air olahan. Reaksi kation dan oksigen menghasilkan oksidasi logam yang sukar larut dala air sehingga dapat mengendap.

\section{E. Kalium Permanganat $\left(\mathrm{KMnO}_{4}\right)$}

Kalium permanganat adalah oksidator kuat. Reagen ini dapat diperoleh dengan mudah, tidak mahal, dan tidak membutuhkan indicator terkecuali untuk larutan yang amat encer. Satu tetes $0,1 \mathrm{~N}$ permanganat memberikan warna merah muda yang jelas pada volume dari larutan yang biasa dipergunakan dalam sebuah titrasi. Warna ini digunakan untuk mengindikasi kelebihan reagen tersebut.

\section{F. EDTA}

EDTA adalah ligan seksidentat yang dapat berkoordinasi dengan suatu ion logam lewat kedua nitrogen dan keempat gugus karboksil-nya atau disebut ligan multidentat yang mengandung lebih dari dua atom koordinasi per molekul, misalnya asam 1,2 diaminoetanatetraasetat (asametilenadiamina tetraasetat, EDTA) yang mempunyai dua atom nitrogen penyumbang dan empat atom oksigen penyumbang dalam molekul (Rival, 1995).

\section{Metode Penelitian}

\section{A. Tempat dan Waktu Penelitian}

\section{Tempat Penelitian}

Air lindi Tempat Pembuangan Akhir (TPA) sampah Batu Layang Kota Pontianak ditentukan sebagai objek/sampel dalam penelitian ini. Sampel air lindi sampah yang digunakan yaitu berasal rembesan air lindi dari tumpukan sampah-sampah baru yang diangkut Tempat Pembuangan Sementara (TPS) yang terdapat di wilayah kota Pontianak

\section{Waktu Penelitian}

Penelitian ini dilakukan selama 7 bulan terhitung dari bulan Januari 2014 sampai dengan Juli 2014. 


\section{B. Pemberian Aerasi}

\section{Alat dan Bahan}

- Alat : bak penampung, aerator, dan nozzle (batu pori)

- Bahan : air lindi Tempat Pembuangan Akhir (TPA) sampah Batu Layang Kota Pontianak

\section{Pelaksanaan}

Air lindi dimasukkan kedalam bak penampung sebanyak 50 liter. Kemudian udara yang berasal dari aerator dialirkan kedalam air lindi melalui selang yang ujungnya diberi nozzle (batu pori). Proses aerasi dibiarkan berlangsung selama 7 hari. Hasil proses aerasi yang digunakan untuk proses selanjutnya dikeluarkan melalui kran bawah.

\section{Pemekatan Logam-Logam Unsur Hara Mikro dengan Penambahan Senyawa $\mathrm{KMnO}_{4}$}

\section{Alat dan Bahan}

- Alat : sentrifuge, beaker $2 \mathrm{~L}$, dan batang pengaduk

- Bahan : air lindi hasil aerasi yang dikeluarkan melalui kran bawah, larutan $\mathrm{CaO}$ 1000 ppm, dan larutan $\mathrm{KMnO}_{4}$ 0.01\%

\section{Pelaksanaan}

Pada $500 \mathrm{ml}$ endapan hasil olahan aerasi dicampurkan kapur tohor (CaO) 1000 ppm dan larutan $\mathrm{KMnO}_{4}$ dengan konsentrasi 0,01\% kedalam beaker $2 \mathrm{~L}$, kemudian di aduk selama \pm 1 menit. Setelah itu diberi perlakuan sentrifugasi. Proses sentrifugasi dilakukan dengan kecepatan $3500 \mathrm{rpm}$ selama 5 menit. Setiap kali melakukan sentrifugasi, endapannya dibiarkan tetap di dalam botol sentrifus, sedangkan cairan yang berada di atas endapan (cairan sisa) dikeluarkan sebelum bahan berikutnya dimasukkan ke dalam botol sentrifus untuk dilakukan proses sentrifugasi pada tahap berikutnya. Sehingga endapan yang terbentuk merupakan akumulasi dari dahan yang dicampur tadi.

\section{Pemekatan Logam-Logam Unsur Hara Mikro dengan Penambahan Senyawa EDTA}

\section{Alat dan Bahan}

- Alat : sentrifuge, beaker $2 \mathrm{~L}$, dan batang pengaduk

- Bahan: air lindi hasil aerasi yang dikeluarkan melalui kran bawah, larutan $\mathrm{CaO}$ 1000 ppm, dan larutan EDTA 0.01\%

\section{Pelaksanaan}

Pada $500 \mathrm{ml}$ endapan hasil olahan aerasi dicampurkan kapur tohor (CaO) 1000 ppm dan Larutan EDTA dengan konsentrasi 0,01\% kedalam beaker 2 L, kemudian di aduk selama \pm 1 menit. Setelah itu diberi perlakuan sentrifugasi. Proses sentrifugasi dilakukan dengan kecepatan $3500 \mathrm{rpm}$ selama 5 menit. Setiap kali melakukan sentrifugasi, endapannya dibiarkan tetap di dalam botol sentrifus, sedangkan cairan yang berada di atas endapan (cairan sisa) dikeluarkan sebelum bahan berikutnya dimasukkan ke dalam botol sentrifus untuk dilakukan proses sentrifugasi pada tahap berikutnya. Sehingga endapan yang terbentuk merupakan akumulasi dari dahan yang dicampur tadi.

\section{Hasil dan Pembahasan}

\section{A. Analisa Pendahuluan}

Analisa pendahuluan dilakukan untuk mengetahui karakteristik awal air lindi yang berasal dari Tempat Pembuangan Akhir (TPA) sampah Batu Layang Pontianak yang digunakan sebagai bahan dalam penelitian. Air lindi yang diambil berasal dari rembesan air lindi yang dihasilkan dari tumpukan-tumpukan sampah. Secara visual, kondisi air lindi yang terdapat pada saluran drianase memiliki warna hitam kecoklatan dan memiliki bau yang tajam. Bau yang ditimbulkan air lindi disebabkan oleh adanya $\mathrm{NH}_{3}$, silfida dan bahan organik yang tergandung dalam air lindi yang berasal dari tumpukan sampah. 
Karakteristik air lindi yang dianalisa pada penelitian ini adalah, $\mathrm{Cu}, \mathrm{Fe}, \mathrm{Mn}$, dan $\mathrm{Zn}$ yang merupakan unsur hara mikro pupuk organik. Sampling dilakukan sebanyak dua kali dengan sampling kedua merupakan perlakuan pengulangan yang dilakukan pada jangka waktu yang berbeda. Hasil analisa pendahuluan karakteristik air lindi tersebut dapat dilihat pada tabel 1

Tabel 1. Hasil Analisa Pendahuluan Karakteristik Air Lindi

\begin{tabular}{|c|c|c|c|c|c|c|}
\hline No. & Sampel & Satuan & $\mathrm{Cu}$ & $\mathrm{Fe}$ & $\mathrm{Mn}$ & $\mathrm{Zn}$ \\
\hline 1 & Sampel Pertama & $\mathrm{mg} / \mathrm{L}$ & 0,236 & 0,345 & 0,216 & 1,369 \\
\hline 2 & Sampel Kedua/Pengulangan & $\mathrm{mg} / \mathrm{L}$ & 1,01 & 89,65 & 2,24 & 2,62 \\
\hline
\end{tabular}

Sumber: Hasil Analisis

Berdasarkan tabel 1, diketahui konsentrasi karakteristik logam-logam unsur hara mikro pada air lindi sampel pertama lebih rendah dibandingkan pada sampel kedua. Hal ini disebakan oleh beberapa faktor diantaranya iklim. Pada sampling pertama dilakukan pada kondisi setelah terjadinya hujan atau musim penghujan sedangkan pada sampling kedua dilakukan pada saat cuaca panas atau musim kemarau.

Hal ini berpengaruh terhadap kuantitas air pembawa kontaminan dari tumpukan sampah dalam proses pembentukan air lindi. Pada musim penghujan kuantitas air yang membawa kontaminan dari tumpukan sampah dalam proses pembentukan air lindi lebih besar sehingga mengalami proses pengenceran yang lebih besar dan menyebabkan konsentrasi karakteristik air lindi yang terbentuk lebih rendah. Dibandingkan pada saat musim kemarau dimana kuantitas air pembawa kontaminan pembentuk air lindi relatif kecil sehingga proses pengencerannya yang terjadi lebih kecil maka konsentrasi karakteristik air lindi yang terbentuk pun lebih besar. Sejalan dengan pendapat Pohland dan Harper (1985), kuantitas dan kualitas air lindi dapat dipengaruhi oleh iklim.

\section{B. Pengaruh Pengolahan Aerasi Terhadap Pemekatan Logam-Logam}

Pengolahan aerasi pada penelitian ini bertujuan untuk mengendapkan logam-logam unsur hara mikro sehingga mengahsilkan efluen air lindi yang lebih pekat terhadap unsurunsur logam, yang kemudian dilanjutkan ke tahap pengolahan selanjutnya.

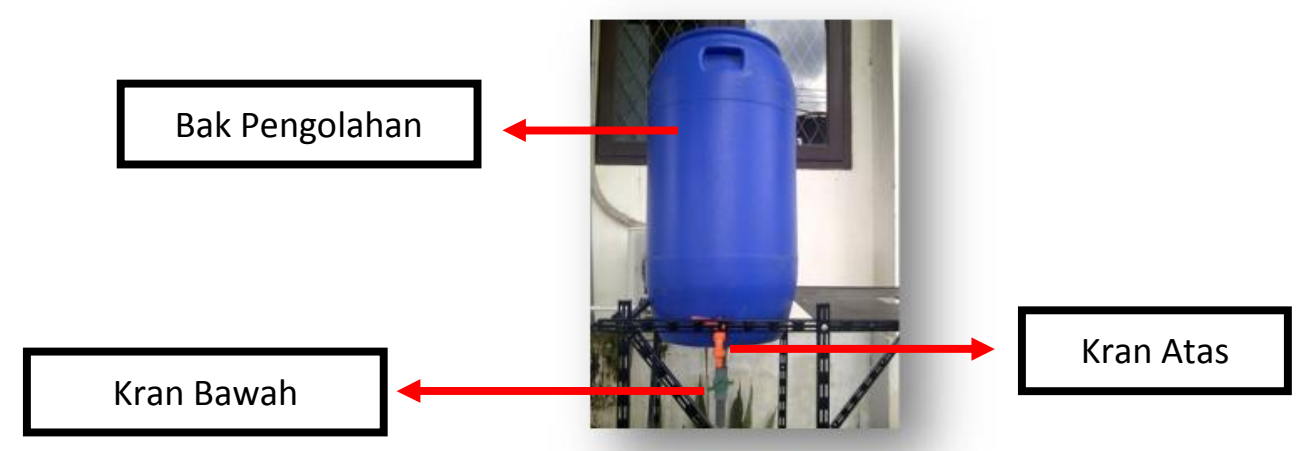

Gambar 1. Bak Pengolahan Aerasi

Dari pengolahan aerasi tadi, maka effluen yang diambil yaitu effluen yang berada di dasar bak pengolahan. Rancangan bak penampung pengolahan aerasi dapat dilihat pada gambar 1. Hasil analisa efluen kran bawah dari pengolahan aerasi ditunjukkan pada tabel 2. 
Tabel 2. Hasil Analisa Efluen Pengolahan Aerasi

\begin{tabular}{|c|c|c|c|c|c|c|}
\hline \multirow{2}{*}{ No. } & \multirow{2}{*}{ Parameter } & \multirow{2}{*}{ Satuan } & \multicolumn{2}{|c|}{ Sampel I } & \multicolumn{2}{|c|}{ Sampel II } \\
\cline { 5 - 7 } & & & Awal & Aerasi & Awal & Aerasi \\
\hline 1 & $\mathrm{Cu}$ & $\mathrm{mg} / \mathrm{L}$ & 0,236 & 0,254 & 1,01 & 10,15 \\
\hline 2 & $\mathrm{Fe}$ & $\mathrm{mg} / \mathrm{L}$ & 0,345 & 15,592 & 89,65 & 713 \\
\hline 3 & $\mathrm{Mn}$ & $\mathrm{mg} / \mathrm{L}$ & 1,369 & 2,494 & 2,62 & 71,75 \\
\hline 4 & $\mathrm{Zn}$ & $\mathrm{mg} / \mathrm{L}$ & 0,216 & 2,728 & 2,24 & 29,65 \\
\hline
\end{tabular}

Sumber: Hasil Analisis

Berdasarkan tabel 2, secara keseluruhan konsentrasi unsur-unsur logam mengalami peningkatan setelah dilakukan pengolahan aerasi. Peningkatan konsentrasi tertinggi pada sampel pertama terjadi pada logam besi (Fe) yaitu sebesar $15,592 \mathrm{mg} / \mathrm{L}$ sedangkan peningkatan konsentrasi terendah terjadi pada logam tembaga $(\mathrm{Cu})$ yaitu sebesar $0,254 \mathrm{mg} / \mathrm{L}$. Peningkatan konsentrasi unsur-unsur logam pada sampel kedua, pada logam besi ( $\mathrm{Fe}$ ) juga terjadi peningkatan konsentrasi tertinggi, dan peningkatan konsentrasi terendah juga terjadi pada logam tembaga (Cu). Berdasarkan data konsentrasi logam-logam yang ada, dapat diketahui efisiensi peningkatan konsentrasi logam setelah pengolahan aerasi melalui persamaan 1.

$$
\% \text { efisiensi }(\% \Delta)=\frac{T 2-T 1}{T 2} \times 100 \%
$$

Keterangan: $\mathrm{T} 1=$ konsentrasi awal logam pada air lindi

$\mathrm{T} 2$ = konsentrasi logam setelah pengolahan aerasi

Efisiensi peningkatan konsentrasi logam-logam unsur hara mikro setelah pengolahan aerasi dapat dilihat pada tabel 3.

Tabel 3. Efisiensi Peningkatan Konsentrasi Logam-Logam Unsur Hara Mikro Pada Pengolahan Aerasi

\begin{tabular}{|c|c|c|c|c|c|}
\hline \multirow{2}{*}{ No. } & \multirow{2}{*}{ Parameter } & Satuan & Sampel I & Sampel II & \multirow{2}{*}{ Rata-rata } \\
\cline { 4 - 5 } & & & Efisiensi & Efisiensi & \\
\hline 1 & $\mathrm{Cu}$ & $\%$ & 7,09 & 90,05 & 48,57 \\
\hline 2 & $\mathrm{Fe}$ & $\%$ & 97,79 & 87,43 & 92,61 \\
\hline 3 & $\mathrm{Mn}$ & $\%$ & 45,11 & 96,35 & 70,73 \\
\hline 4 & $\mathrm{Zn}$ & $\%$ & 92,08 & 92,45 & 92,27 \\
\hline
\end{tabular}

Sumber: Hasil Analisis.

Pada tabel 3, efisiensi rata-rata tertinggi terjadi pada logam besi ( $\mathrm{Fe}$ ) yaitu sebesar 92,61 \% sedangkan terendah terjadi pada logam tembaga (Cu) 48,57 \%. Menurut Park et al., (1994), proses aerasi dapat menyebabkan suasana menjadi lebih oksidatif. Selanjutnya Suriawiria (1993) mengemukakan bahwa suasana yang lebih oksidatif dapat menyebabkan logam terlarut menjadi mengendap.

\section{Pengaruh Pemberian Larutan $\mathrm{CaO}$ dengan Senyawa Pengkelat $\mathrm{KMnO}_{4}$ dan Senyawa Pengkelat EDTA terhadap Logam-Logam.}

Penambahan larutan $\mathrm{CaO} 1000$ ppm bertujuan untuk merubah kelarutan logam-logam unsur hara mikro menjadi lebih rendah, sehingga logam-logam tersebut menjadi lebih mudah diendapkan, yang selanjutnya dioptimalkan kembali dengan penambahan senyawa pengkelat. Penambahan larutan-larutan tersebut dilakukan dengan perbandingan volume larutan 1:1:1 yang masing-masing larutan diberikan sebanyak $500 \mathrm{~mL}$.

Pada saat pencampuran air lindi dengan larutan $\mathrm{CaO} 1000$ ppm, campuran menunjukkan adanya flok-flok dalam larutan. Dalam hal ini, penambahan larutan $\mathrm{CaO}$ menyebabkan $\mathrm{pH}$ 
larutan menjadi meningkat hingga mencapai 9,11 yang merupakan larutan dalam kondisi basa. Menurut Nurhasanah (2012), semakin tinggi pH berarti semakin tinggi pula konsentrasi $\mathrm{OH}^{-}$ dalam larutan dan ini menyebabkan semakin besar pula peluang untuk terjadinya interaksi antara logam-logam terlarut dengan $\mathrm{OH}^{-}$yang ada dalam larutan. Dari hasil interaksi antara $\mathrm{OH}^{-}$dengan logam-logam inilah membentuk flok-flok dalam larutan yang mudah untuk diendapkan.

\section{Pengaruh Pengaruh Penambahan Larutan $\mathrm{KMnO}_{4}$}

Penambahan senyawa $\mathrm{KMO}_{4}$ berperan untuk mengoptimalkan pemekatan logam-logam unsur hara mikro yaitu dengan mengoksidasi logam-logam yang tidak dapat berinteraksi pada saat penambahan Larutan $\mathrm{CaO}$ sehingga mengakibatkan logam-logam tersebut menjadi mengendap. Kemudian untuk mendapakan endapan yang mengandung unsur hara mikro tadi maka dilakukan proses sentrifugasi.

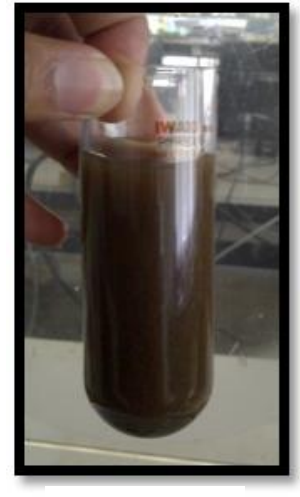

Sebelum

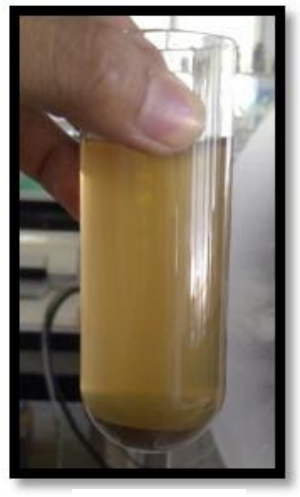

Setelah

Gambar 2. Perubahan Campuran Larutan Setelah Diberikan Proses Sentrifugasi

Endapan yang terbentuk dari proses sentrifugasi merupakan hasil produk akhir yang digunakan sebagai pupuk kaya akan logam-logam unsur hara mikro. Hasil analisis karakteristik endapan hasil proses sentrifugasi dapat dilihat pada Hasil analisis karakteristik endapan hasil penambahan senyawa $\mathrm{KMnO}_{4}$ dapat dilihat pada tabel 4 .

Tabel 4. Hasil Analisa Peningkatan Konsentrasi Logam Dengan Penambahan Senyawa $\mathrm{KMnO}_{4}$

\begin{tabular}{|c|c|c|c|c|c|c|c|c|}
\hline \multirow{2}{*}{ No. } & \multirow{2}{*}{ Parameter } & \multirow{2}{*}{ Satuan } & \multicolumn{3}{|c|}{ Sampel I } & \multicolumn{3}{c|}{ Sampel II } \\
\cline { 5 - 10 } & & & Awal & Aerasi & KMnO $_{4}$ & Awal & Aerasi & KMnO $_{4}$ \\
\hline 1 & $\mathrm{Cu}$ & $\mathrm{mg} / \mathrm{L}$ & 0,236 & 0,254 & 3.500 & 1,01 & 10,15 & 5.000 \\
\hline 2 & $\mathrm{Fe}$ & $\mathrm{mg} / \mathrm{L}$ & 0,345 & 15,592 & 19.900 & 89,65 & 713 & 1.300 \\
\hline 3 & $\mathrm{Mn}$ & $\mathrm{mg} / \mathrm{L}$ & 1,369 & 2,494 & 600 & 2,62 & 71,75 & 400 \\
\hline 4 & $\mathrm{Zn}$ & $\mathrm{mg} / \mathrm{L}$ & 0,216 & 2,748 & 500 & 2,24 & 29,65 & 500 \\
\hline
\end{tabular}

Sumber: Hasil Analisis

Berdasarkan tabel 4, konsentrasi logam-logam unsur hara mikro secara keseluruhan kembali berhasil mengalami peningkatan. Konsentrasi tertinggi pada sampel pertama terdapat pada logam besi yaitu sebesar $19.900 \mathrm{mg} / \mathrm{L}$ sedangkan konsentrasi terendah terdapat pada logam seng $(\mathrm{Zn})$ yaitu sebesar $500 \mathrm{mg} / \mathrm{L}$. Pada sampel kedua konsentrasi tertinggi terdapat 
pada logam ( $\mathrm{Fe}$ ) yaitu sebesar $1.300 \mathrm{mg} / \mathrm{L}$ sedangakan konsentrasi terendah terdapat pada logam mangan ( $\mathrm{Mn}$ ) yaitu sebesar $400 \mathrm{mg} / \mathrm{L}$.

Berdasarkan data konsentrasi logam-logam setelah penambahan senyawa $\mathrm{KMnO}_{4}$, dapat diketahui efisiensinya melalui persamaan 1 . Efisiensi peningkatan konsentrasi logam-logam unsur hara mikro setelah pengolahan aerasi dapat dilihat pada tabel 5 .

Tabel 5. Efisiensi Peningkatan Konsentrasi Logam-Logam Unsur Hara Mikro Dengan Penambahan Senyawa $\mathrm{KMnO}_{4}$

\begin{tabular}{|c|c|c|c|c|c|}
\hline \multirow{2}{*}{ No. } & Parameter & Satuan & Sampel I & Sampel II & \multirow{2}{*}{ Rata-rata } \\
\cline { 4 - 5 } & & & Efisiensi & Efisiensi & \\
\hline 1 & $\mathrm{Cu}$ & $\%$ & 99,99 & 99,97 & 99,98 \\
\hline 2 & $\mathrm{Fe}$ & $\%$ & 99,99 & 93,10 & 96,55 \\
\hline 3 & $\mathrm{Mn}$ & $\%$ & 99,77 & 99,35 & 99,56 \\
\hline 4 & $\mathrm{Zn}$ & $\%$ & 99,95 & 99,55 & 99,75 \\
\hline
\end{tabular}

Sumber: Hasil Analisis

Berdasarkan tabel 4.5, efisiensi rata-rata tertinggi terjadi pada logam tembaga ( $\mathrm{Cu}$ ) yaitu sebesar 99,98 \% sedangkan efisiensi terendah terjadi pada logam besi $(\mathrm{Fe})$ yaitu sebesar 96,55 $\%$.

\section{Penambahan Larutan EDTA}

Penambahan larutan EDTA 0,01 \% juga berperan dalam mengoptimalkan pemekatan terhadap logam-logam unsur hara mikro yang tidak dapat berinteraksi pada saat penambahan $\mathrm{CaO}$ dengan mengikat logam-logam dengan kedua nitrigen dan keempat gugus karboksilatnya atau disebut ligan multidentat yang mengandung lebih dari gdua atom koordinasi per molekul. Konsentrasi logam-logam yang didapat yang terdapat dalam endapan dari hasil pengolahan dengan penambahan EDTA 0,01\% dapat dilihat pada tabel 6 .

Tabel 6. Hasil Analisa Peningkatan Konsentrasi Logam Dengan Penambahan Senyawa EDTA

\begin{tabular}{|c|c|c|c|c|c|c|c|c|}
\hline \multirow{2}{*}{ No. } & \multirow{2}{*}{ Parameter } & \multirow{2}{*}{ Satuan } & \multicolumn{4}{|c|}{ Sampel I } & \multicolumn{3}{c|}{ Sampel II } \\
\cline { 5 - 10 } & & & Awal & Aerasi & EDTA & Awal & Aerasi & EDTA \\
\hline 1 & $\mathrm{Cu}$ & $\mathrm{mg} / \mathrm{L}$ & 0,236 & 0,254 & 300 & 1,01 & 10,15 & 400 \\
\hline 2 & $\mathrm{Fe}$ & $\mathrm{mg} / \mathrm{L}$ & 0,345 & 15,592 & 2.300 & 89,65 & 713 & 5.000 \\
\hline 3 & $\mathrm{Mn}$ & $\mathrm{mg} / \mathrm{L}$ & 1,369 & 2,494 & 13.900 & 2,62 & 71,75 & 1.300 \\
\hline 4 & $\mathrm{Zn}$ & $\mathrm{mg} / \mathrm{L}$ & 0,216 & 2,748 & 300 & 2,24 & 29,65 & 500 \\
\hline
\end{tabular}

Sumber: Hasil Analisis

Berdasarkan tabel 6, bahwa konsentrasi logam-logam juga berhasil meningkat kembali. Konsentrasi tertinggi pada sampel pertama terdapat pada logam mangan ( $\mathrm{Mn}$ ) yaitu sebesar $13.900 \mathrm{mg} / \mathrm{L}$ sedangkan konsentrasi terendah terdapat pada logam seng ( $\mathrm{Zn}$ ) dan tembaga (Cu). Pada sampel kedua konsentrasi tertinggi terdapat pada logam ( $\mathrm{Fe}$ ) yaitu sebesar 5.000 $\mathrm{mg} / \mathrm{L}$ sedangakan konsentrasi terendah terdapat pada logam tembaga $(\mathrm{Cu})$.

Berdasarkan data konsentrasi logam-logam setelah penambahan senyawa EDTA, dapat diketahui efisiensinya melalui persamaan 1 . Efisiensi peningkatan konsentrasi logam-logam unsur hara mikro setelah pengolahan aerasi dapat dilihat pada tabel 7 . 
Tabel 7. Efisiensi Peningkatan Konsentrasi Logam-Logam Unsur Hara Mikro Logam Dengan Penambahan Senyawa EDTA

\begin{tabular}{|c|c|c|c|c|c|}
\hline \multirow{2}{*}{ No. } & \multirow{2}{*}{ Parameter } & \multirow{2}{*}{ Satuan } & Sampel I & Sampel II & \multirow{2}{*}{ Rata-rata } \\
\hline & & & Efisiensi & Efisiensi & \\
\hline 1 & $\mathrm{Cu}$ & $\%$ & 99,92 & 99,74 & 99,83 \\
\hline 2 & $\mathrm{Fe}$ & $\%$ & 99,98 & 98,21 & 99.10 \\
\hline 3 & $\mathrm{Mn}$ & $\%$ & 99,99 & 99,72 & 99,86 \\
\hline 4 & $\mathrm{Zn}$ & $\%$ & 99,93 & 99,95 & 99,94 \\
\hline
\end{tabular}

Sumber: Hasil Analisis

Berdasarkan tabel 7, efisiensi rata-rata tertinggi terjadi pada logam seng ( $\mathrm{Zn}$ ) yaitu sebesar 99,94\% sedangkan efisiensi terendah terjadi pada logam besi (Fe) yaitu sebesar $99,10 \%$.

\section{Potensi Air Lindi Sebagai Bahan Pupuk Organik}

Berdasarkan hasil akhir pemekatan konsentrasi unsur hara mikro yang diperoleh, pada penambahan senyawa $\mathrm{KMnO}_{4}$, konsentrasi logam besi (Fe) pada sampel pertama meningkat pesat dibandingkan dengan unsur-unsur logam yang lainnya yaitu mencapai $19.900 \mathrm{mg} / \mathrm{L}$. Hal yang sama terjadi pada saat penambahan senyawa EDTA, konsentrasi logam yang meningkat pesat dari logam-logam lainnya hingga melebihi stadar persyaratan pupuk organik terjadi pada logam mangan $(\mathrm{Mn})$ pada sampel pertama yaitu sebesar $13.900 \mathrm{mg} / \mathrm{L}$ dibandingkan dengan konsentrasi yang telah ditentukan untuk logam mangan (Mn) yaitu sebesar $5.000 \mathrm{mg} / \mathrm{L}$.

Menurut Davis dan Masten (2004) mengemukakan bahwa pada $\mathrm{pH}$ diatas netral $\pm \mathrm{pH}$, logam-logam terlarut seperti $\mathrm{Cu}, \mathrm{Zn}$, dan $\mathrm{Pb}$ memilki solubilitas yang minimum dan akan membentuk endapan dalam bentuk senyawa hidoksida. Namun pada $\mathrm{pH}>9$, ketiga logam tersebut akan membetuk senyawa kompleks yang mudah larut. Sedangkan menurut penelitian Nurhasah (2012), pada kondisi pH > 9, meskipun ada beberapa logam mikro terlarut yang mengalami pelarutan kembali yaitu seperti $\mathrm{Cu}, \mathrm{Zn}$, dan $\mathrm{Pb}$ tadi, namun ada pula logam mikro lainnya yang masih mengalami pengendapan seperti $\mathrm{Mn}, \mathrm{Fe}$, dan $\mathrm{Cr}$. Hal ini disebabkan bahwa logam-logam terlarut tadi beriteraksi dengan $\mathrm{OH}^{-}$atau berinteraksi dengan koloid membentuk senyawa yang mudah mengendap. Sejalan dengan penelitian yang dilakukan, bahwa saat penambahan senyawa $\mathrm{KMnO}_{4} \mathrm{pH}$ yang terbentuk sebesar 9,10 sedangkan pada penambahan senyawa EDTA pH yang terbentuk sebesar 9,13. Kondisi pH seperti ini, mendukung pernyataan-pernyataan yang dikemukakan diatas dengan nilai konsentrasi logam yang didapat dalam penelitian yang dilakukan.

Konsentrasi besi $(\mathrm{Fe})$ dan mangan $(\mathrm{Mn})$ yang berlebihan menyebabkan toksik bagi tanaman. Kelebihan besi ( $\mathrm{Fe}$ ) serta mangan ( $\mathrm{Mn}$ ) mengakibatkan defisiensi fosfor $(\mathrm{P})$ yaitu kekurangan unsur hara fosfor. Ini disebabkan unsur-unsur logam yang berlebih tadi dapat mengikat unsur fosfor (P) pada sumber energi ATP. Fosfor merupakan unsur penting dalam penyusun Adenosin Triphosphate (ATP) yang secara langsung berperan dalam proses penyimpanan dan transfer energi yang terkait dalam proses metabolisme tanaman (Dobermann dan Fairhurst, 2000). Sebagai salah satu dampak dari gejala tersebut antara lain yaitu proses fotosintesis menjadi terhambat, sehingga proses pertumbuhan tanaman pun terhambat.

Sebagai upaya untuk mengatasi unsur hara yang berlebihan tadi agar hasil dari penelitian ini dapat diaplikasikan, maka dilakukan dengan cara pengapuran (Breemen dan Moorman, 1978). Soepardi (1983) mengemukakan bahwa ada dua macam bahan kapur yang melimpah dan sering dimanfaatkan dalam pertanian yaitu Kalsit $\left(\mathrm{CaCO}_{2}\right)$ dan Dolomit $\left(\mathrm{CaMg}\left(\mathrm{CO}_{2}\right)_{2}\right)$. Pemberian kapur dapat meningkatkan aktivitas jasad renik dalam merombak 
bahan organik sehingga pengikatan besi oleh bahan organik meningkat, akibatnya serapan besi oleh tanaman menurun (Syafruddin, 1990).

\section{Kesimpulan}

A. Kesimpulan

a. Peningkatan konsentrasi logam-logam unsur hara mikro pada pengolahan aerasi antara lain $\mathrm{Cu}(8,07 \%)$, Fe (92,61 \%), Mn (70,73 \%) dan Zn (92,27\%). Efisiensi peningkatan konsentrasi logam tertinggi terjadi pada logam besi (Fe). Sedangkan efisiensi terendah terjadi pada logam tembaga $(\mathrm{Cu})$

b. Penambahan senyawa $\mathrm{KMnO}_{4}$ memiliki efektifitas dalam pemekatan logam-logam unsur hara mikro. Rata-rata efisiensi peningkatan konsentrasi logam-logam unsur hara mikro antara lain Cu (99,98 \%), Fe ( 96,55 \%), Mn (99,56 \%) dan Zn (99,75\%). Efisiensi peningkatan konsentrasi logam tertinggi terjadi pada logam tembaga (Cu). Sedangkan efisiensi terendah terjadi pada logam besi ( $\mathrm{Fe})$

c. Penambahan senyawa EDTA memiliki efektifitas dalam pemekatan logam-logam unsur hara mikro. Rata-rata efisiensi peningkatan konsentrasi logam-logam unsur hara mikro antara lain Cu (99,83\%), Fe ( 99,10 \%), Mn (99,86 \%) dan Zn (99,86\%). Efisiensi peningkatan konsentrasi logam tertinggi terjadi pada logam mangan (Mn). Sedangkan efisiensi terendah terjadi pada logam besi ( $\mathrm{Fe})$.

\section{Daftar Pustaka}

Arya, K. dan G. M. Gilar. 2008. Pupuk Cair Organik Tanah Surga. http://tanahsurga.blogspot.com/2008/09/pupuk-cair--organik-tanah-surga.html. Diakses pada tanggal 12 Juni 2011.

Barus. 2002. Pengantar Limnologi. Jurusan Biologi FMIPA Universitas Sumatra Utara. Medan.

Breemen, N.V. and F.R. Moorman. 1978. Iron Toxic Soils. P 781-800. In soils and rice. Los Banos. Philippines.

Davis dan Masten. 2004. Principles of Environment Engineering and Science. Mc Graw Hill. Michigan State Unversity. USA.

Dobermann, A. dan T. Fairhurst. 2000. Rice : Nutrient Disorders \& Nutrient Management. Potash \& Potash Institute/Potash \& Potash Institute of Canada. Canada.

Nemerow, L. Nelson dan A. Dasgupta. 1991. Industrial and Hazardous Waste Treatment. Van Nostrand-Reinhold, New York.

Nurhasanah. 2012. Pengolahan Lindi dan Potensi Pemanfaatannya sebagai Pupuk Cair untuk Mendukung Pengembangan TPA Sampah Lestari. Surabaya.

Park, K. M., K. H. Muhvich, R. A. Myers, L. Marzeilla. 1994. Effects of Hyperbaric Oxygen in Infectious Diseases : Basic Mechanisms.

Rival, H. 1995. Asas Pemeriksaan Kimia. Universitas Indonesia Press. Jakarta.

Suriawiria, U. 1993. Mikrobiologi Air dan Dasar-Dasar Pengolahan Buangan secara Biologis. Alumni. Bandung.

Soepardi, G. 1983. Sifat dan Ciri Tanah. Departemen Ilmu Tanah, Institut Pertanian Bogor. Bogor. 591 hal.

Syafruddin, A.K.m1990. Usaha Tani Lahan Sawah Bukaan Baru. Hal-343-350. Dalam A. Taher, M.H. Abbas dan Yurnalis, ed. Pengolahan Sawah Bukaan Baru: Prospek dan Masalah. Fakultas Pertanian Universitas Ekasakti dan Balai Penelitian Tanaman Pangan Sukarami. Padang 